\title{
BMJ Open How will South Africa's mandatory salt reduction policy affect its salt iodisation programme? A cross-sectional analysis from the WHO-SAGE Wave 2 Salt \& Tobacco study
}

Karen Charlton, ${ }^{1,2}$ Lisa Jayne Ware, ${ }^{3,4}$ Jeannine Baumgartner, ${ }^{5}$ Marike Cockeran, ${ }^{6}$ Aletta E Schutte, ${ }^{3,7}$ Nirmala Naidoo, ${ }^{8}$ Paul Kowal ${ }^{8,9}$

To cite: Charlton K, Ware LJ, Baumgartner J, et al. How will South Africa's mandatory salt reduction policy affect its salt iodisation programme? A cross-sectional analysis from the WHO-SAGE Wave 2 Salt \& Tobacco study. BMJ Open 2018;8:e020404. doi:10.1136/ bmjopen-2017-020404

- Prepublication history for this paper is available online. To view these files, please visit the journal online (http://dx.doi. org/10.1136/bmjopen-2017020404).

Received 2 November 2017 Revised 5 February 2018 Accepted 9 February 2018

Check for updates

For numbered affiliations see end of article.

Correspondence to

Dr Karen Charlton;

karenc@uow.edu.au

\section{ABSTRACT}

Objective The WHO's global targets for noncommunicable disease reduction recommend consumption of $<5 \mathrm{~g}$ salt/day. In 2016 , South Africa was the first country to legislate maximum salt levels in processed foods. South Africa's salt iodisation fortification programme has successfully addressed iodine deficiency but information is dated. Simultaneous monitoring of sodium reduction and iodine status is required to ensure compatibility of the two public health interventions.

Design/setting/participants A nested cohort design within WHO's 2015 Study on global AGEing and adult health ( $n=2887$ ) including individuals from households across South Africa. Randomly selected adults $(n=875)$ provided 24-hour and spot urine samples for sodium and iodine concentration analysis (the primary and secondary outcome measures, respectively). Median 24-hour urinary iodine excretion (UIE) and spot urinary iodine concentrations (UIC) were compared by salt intakes of $<5 \mathrm{~g} /$ day, $5-9 \mathrm{~g} /$ dayand $>9 \mathrm{~g} /$ day.

Results Median daily sodium excretion was equivalent to $6.3 \mathrm{~g}$ salt/day (range $1-43 \mathrm{~g} /$ day); $35 \%$ had urinary sodium excretion values within the desirable range $(<5 \mathrm{~g}$ salt/ day), $37 \%$ had high values (5-9 g salt/day) and $28 \%$ had very high values (>9g salt/day). Median UIC was $130 \mu \mathrm{g} / \mathrm{L}$ (IQR=58-202), indicating population iodine sufficiency $(\geq 100 \mu \mathrm{g} / \mathrm{L})$. Both UIC and UIE differed across salt intake categories $(p<0.001)$ and were positively correlated with estimated salt intake ( $r=0.166$ and 0.552 , respectively; both $p<0.001$ ). Participants with salt intakes of $<5 \mathrm{~g} /$ day were not meeting the Estimated Average Requirement for iodine intake ( $95 \mu \mathrm{g} / \mathrm{day})$.

Conclusions In a nationally representative sample of South African adults, the association between indicators of population iodine status (UIC and UIE) and salt intake, estimated using 24-hour urinary sodium excretion, indicate that low salt intakes may compromise adequacy of iodine intakes in a country with mandatory iodisation of table salt. The iodine status of populations undergoing salt reduction strategies needs to be closely monitored to prevent re-emergence of iodine deficiency.
Strengths and limitations of this study

- The study uses the current gold standard of 24-hour urine to assess sodium intake.

- Timing of the study was immediately prior to legislation of maximum permitted salt levels in processed foods.

- The large sample size includes coastal and inland populations from across the country.

- Lack of dietary data precludes assessment of sources of iodine or sodium.

- The data are only for adults and not children.

\section{INTRODUCTION}

Iodine deficiency remains the largest preventable cause of brain damage and mental impairment worldwide. Thyroid hormone production requires an adequate supply of iodine from the diet, and is essential to metabolism and growth across the life cycle. As well as cretinism in its most severe form, iodine deficiency can also result in miscarriages, stillbirths and impaired psychomotor development and behavioural problems in children born to iodine-deficient mothers. ${ }^{1}$ To prevent iodine deficiency disorders, the WHO has endorsed universal salt iodisation (USI), where all salt for human and animal consumption is iodised..$^{23}$ USI is hailed as a public health success story, as $75 \%$ of the world's population was estimated in 2016 to use iodised salt in a total of 130 countries. ${ }^{45}$ The 2016 global estimate of iodine nutrition, based on surveys of school-age children conducted between 2002 and 2016, shows that the iodine intake is insufficient in 15 countries, sufficient in 102 and excessive in $10 .{ }^{6}{ }^{7}$ Among the 15 countries with insufficient intake, only two are classified as moderately deficient and 13 as mildly deficient. 
This represents a reduction in the number of countries with insufficient iodine intake, from 32 in $2011,{ }^{8}$ to 25 countries in $2015,{ }^{9}$ to 15 countries in $2016^{6}$ which reflects continuing progress to improved coverage of iodised salt at the national level. ${ }^{10}$

In South Africa, mandatory iodisation of table salt, at a level of 40-60 ppm, replaced voluntary iodisation in December 1995, using potassium iodate as the fortificant $^{11}$ because of its stability in warm climates, ${ }^{12}$ rather than potassium iodide that is used in North America and Europe. The level of fortification was subsequently revised in 2007 to allow a wider range, namely $35-65$ ppm. ${ }^{13}$ The iodisation programme has effectively addressed iodine deficiency in the country, but there are some loopholes in the programme, such as the domestic use of non-iodised agricultural salt in some regions. ${ }^{1314}$ In $2005,78 \%$ of households nationwide purchased salt for household uses from typical food stores. At the same time, $8 \%-37 \%$ of households across all the provinces of South Africa obtained salt for household use from 'unconventional' channels such as agricultural and other sources of non-iodised salt. Under the legislation, salt used in the manufacturing of processed foods and salt packaged in bags of at least $20 \mathrm{~kg}$ are also exempted from mandatory iodisation. ${ }^{11}$ In 2005 , $77 \%$ of households in the country used adequately iodised salt, described as salt containing more than $15 \mathrm{ppm}$ of iodine. ${ }^{13}$ However, data on the iodine status of the South African population are outdated and a national survey was last conducted in $2005 .{ }^{14}$ At that time, South African women and children aged 6-9 years old were found to have an optimal iodine status (ie, median urinary iodine concentration (MUIC) $100-199 \mathrm{mg} / \mathrm{L},<20 \%$ with UIC levels $<50 \mathrm{mg} / \mathrm{L})^{15}$ which indicated a well-functioning salt iodisation programme. ${ }^{616}$

At the same time as salt iodisation efforts around the world are being celebrated, there is a global focus on salt reduction efforts to lower population-level blood pressure (BP). The WHO and World Health Assembly targets to reduce non-communicable diseases include a $30 \%$ reduction in population salt intake by $2025 .{ }^{17}{ }^{18}$ South Africa was the first country to implement mandatory legislation in July 2016 for maximum salt levels permitted in a wide range of processed foods ${ }^{19}$ that are significant contributors to the sodium intake of the population. ${ }^{20-23}$ The legislation is predicted to decrease population-level salt intake by $0.85 \mathrm{~g} / \mathrm{day}^{24}$ and reduce annual deaths from cardiovascular diseases by $11 \%$. This public health strategy is estimated to save the government US $\$ 51.25$ million/ year in healthcare costs; and save households more than US $\$ 4$ million/year in out-of-pocket medical expenses. ${ }^{25}$

Since salt is the vehicle for iodine fortification, successful campaigns to reduce salt intake would also likely result in reduced iodine intake. ${ }^{26}$ Dietary modelling conducted in the Netherlands estimated the effect of $12 \%, 25 \%$ and $50 \%$ decreases in salt from processed foods and table salt. ${ }^{26}$ Only at a $50 \%$ salt decrease would iodine intake become inadequate for a small percentage of the population which, at that time, confirmed a lack of conflict between population-wide strategies of decreasing salt while ensuring adequate consumption of iodised salt to prevent iodine deficiency. We have previously reported no difference in MUIC across categories of sodium excretion equivalent to salt intakes of $<5 \mathrm{~g} /$ day, $5-9 \mathrm{~g} /$ day and $>9 \mathrm{~g}$ /day in a convenience sample of 262 adult men and women in Cape Town in $2004 .^{27}$ It was concluded that this was because much of the dietary salt consumed was provided from non-iodinated sources, presumably in salt added to processed foods. Given the introduction of the salt reduction legislation, it is timeous to assess the iodine status of the South African population, according to salt intakes.

The aim of the current study was to simultaneously measure sodium (Na) and iodine in 24-hour and spot urinary collections in an adult cohort to determine whether lower salt intakes are associated with a suboptimal iodine status.

\section{METHODS}

A nested observational study was conducted as part of Wave 2 of the WHO Study on global AGEing and adult health (WHO-SAGE). WHO-SAGE is a multinational cohort study examining the health and well-being of adult populations and the ageing process. Two waves of this longitudinal study have been completed in China, Ghana, India, Mexico, Russia and South Africa. ${ }^{28}$ In total, 42464 respondents were recruited across the six countries for Wave 1 (2007-2010), including 4223 respondents in South Africa (9\% 18-49 years; $40 \%$ 50-59 years; $51 \%$ $60+$ years). Respondents were recruited from selected probability sampled enumeration areas (EA) using a multistage cluster sampling strategy, with stratification by province, residence and race. Urine capture was included as part of SAGE South Africa Wave 2 data collection. The sampling strategy was designed to account for attrition, where households were classified into the following mutually exclusive categories: (1) SAGE Wave 1 follow-up households with one or more members aged 50 years or more targeted for selection; (2) new households with one or more members aged 50 years or more; (3) SAGE Wave 1 follow-up households which include residents aged 18-49 targeted for selection; or (4) new households which include residents aged 18-49. Further detail on the sampling and recruitment strategy can be found in the study protocol paper. ${ }^{29}$

For Wave 2 data collection in 2015, twenty survey teams (one nurse and three interviewers per team) simultaneously collected data and samples from respondents across all provinces in the country over a 5-month period. Respondents who were recruited to provide urine collections $(n=1200)$ were sampled from among the first households visited within each EA, as a means to simplify logistics and reduce sample transit time to the central Durban laboratory.

Inclusion criteria for urine collection were: respondent must be part of the WHO-SAGE cohort, with no 
indication of urinary incontinence or other condition that could impede 24-hour urine collection; and if female, not menstruating, pregnant or breast feeding on the day of collection.

\section{Study measures}

All survey teams were trained with support from WHO Geneva. As part of the larger survey, anthropometry, household and individual questionnaires, blood sampling, BP and physical function tests were completed as described previously in SAGE Wave $1 .^{28}$ Interviewers spoke the respondents' home languages with consent forms available in the most widely spoken languages for each area. All respondents gave free and informed consent prior to taking part. The study complied with ethical principles ${ }^{30}$ and all procedures involving human subjects were approved by the WHO Ethics Review Committee (RPC149), and North-West University and University of Witwatersrand Research Ethics Committees in South Africa.

\section{Urine collection}

The protocol used for collection of 24-hour urine samples followed the WHO/Pan American Health Organization guidelines. ${ }^{31}$ Respondents were requested to collect all urine produced for 24 hours, excluding the first pass urine on day 1, but including the first urine of the following morning (day 2) in a 5 L plastic container containing $1 \mathrm{~g}$ thymol as preservative in South Africa. The spot sample was collected without preservative from the second urine passed on day 1 (marking the start of the 24-hour collection) and decanted into three $15 \mathrm{~mL}$ Porvair tubes (Porvair Sciences, Leatherhead, UK) then kept in a cool box powered by the fieldwork vehicles. The next morning, the 24-hour sample volumes were recorded and aliquots ( $4 \times$ Porvair tubes) generated with all samples then shipped to the laboratory, maintaining the cold chain. Thymol, a crystalline natural derivative of the thyme plant, was used as a preservative. Thymol has been shown to prevent changes in urinary creatinine, sodium and potassium concentrations for up to 5 days. ${ }^{32}$ Incomplete 24-hour urine collections were assumed if: total volume $\leq 300 \mathrm{~mL}$; or creatinine excretion $\leq 4 \mathrm{mmol}$ / day (women) or $\leq 6 \mathrm{mmol} /$ day (men) ${ }^{33}$

\section{Urine analysis}

Sodium was determined using the indirect ion selective electrode method and creatinine analysed using the standardised urinary Jaffe kinetic method (Beckman Coulter Synchron DXC600/800 System). The WHO population target for salt intake is $5 \mathrm{~g}$ salt $(\mathrm{NaCl})$ per day, equivalent to urinary sodium excretion of $1950 \mathrm{mg}$ (or $85 \mathrm{mmol}) / 24$ hours. Sodium $(\mathrm{mmol} / \mathrm{L})$ in the 24-hour urine sample was converted to salt (g/day) using the formula: $\mathrm{Na} \mathrm{mmol} / \mathrm{L} * 24$ hours volume $(\mathrm{L}) * 23.1$ (molecular weight of sodium)/390 (390 mg sodium per $1 \mathrm{~g}$ sodium chloride (salt)). With the exception of iodine, all South African samples were analysed at a single laboratory in Durban, South Africa (Global Clinical and Viral Laboratories). Urine samples for iodine analysis were stored at $-20^{\circ} \mathrm{C}$ and batch analysed using the Sandell-Kolthoff method with ammonium persulfate digestion and microplate reading ${ }^{34}$ at the North-West University Centre of Excellence for Nutrition. The laboratory participates successfully in the Program to Ensure the Quality of Urinary Iodine Procedures (US Centers for Disease Control and Prevention, Atlanta, GA, USA) ${ }^{35}$ To convert urinary excretion values to estimated daily iodine intake ( $\mu \mathrm{g} /$ day), urinary iodine excretion (UIE; $\mu \mathrm{g} / 24$ hours) values were divided by 0.92 , based on the assumption that approximately $92 \%$ of dietary iodine is excreted in urine. A median of $<100 \mu \mathrm{g}$ iodine/L indicates population-level deficiency (there are no reference ranges for individuals). ${ }^{36}$

\section{Data capture, analysis and statistical power}

All data were captured using an electronic data capture system and uploaded to a secure central server for data cleaning and analysis. The nested cohort sample size for the primary outcome measure of 24-hour urine sodium was calculated as previously described. ${ }^{29}$ Allowing for error in 24-hour sample collection (incomplete or missing samples) in this complex field study, a target subsample size of 1200 was randomly selected from the main SAGE Wave 2 cohort, and those with incomplete or missing samples excluded from the analysis. The sample size used for this analysis was deemed adequate based on recommendations of $\mathrm{WHO}$ (2007) that states a sample size between 600 and 900 is sufficient to have a reasonable CI around the coverage estimate for UIC. ${ }^{2}$ More recently, Karmisholt et al recommend that 400 urine samples are required to determine the MUIC of a group with $5 \%$ precision. ${ }^{37}$

Both spot UIC and 24-hour UIE analyses were compared across three categories of 24-hour urinary $\mathrm{Na}$ values, equivalent to salt intakes of $<5 \mathrm{~g} /$ day, $5-9 \mathrm{~g} /$ day and $>9 \mathrm{~g} /$ day. Normality of data was assessed by visual inspection of histograms and the Kolmogorov-Smirnov test. All non-parametric data were reported as median and IQR (25th, 75th percentiles) and continuous variables compared using independent samples MannWhitney U test or independent samples Kruskal-Wallis test. Categorical variables were compared across groups using Pearson's $X^{2}$ test and Fisher's exact test. Data were also analysed according to urinary $\mathrm{Na}$ excretion values and by iodine category (suboptimal: UIC $<100 \mu \mathrm{g} / \mathrm{L}$; iodine replete: 100-299 $\mu \mathrm{g} / \mathrm{L}$; and excessive: $>300 \mu \mathrm{g} / \mathrm{L}$ ). To assess the association between salt intake, body size, UIC and UIE, Spearman's rank order and partial correlations were conducted.

\section{RESULTS}

Complete urinary $\mathrm{Na}$ and iodine data were available in $\mathrm{n}=874$ participants. Sociodemographic characteristics and health indicators of the subsample are compared with 
Table 1 Characteristics of the main (SAGE South Africa Wave 2, 2015) and subsample study cohort

\begin{tabular}{|c|c|c|c|c|c|}
\hline & \multicolumn{2}{|c|}{ Main SAGE cohort $n=2887$} & \multicolumn{2}{|c|}{ Subsample $^{*}=875$} & \multirow[b]{2}{*}{$P$ value } \\
\hline & Median & IQR & Median & IQR & \\
\hline Female, n (\%) & 1939 & 67 & 671 & 77 & $<0.001$ \\
\hline Age (years) & 57 & 46,69 & 55 & 44,67 & 0.468 \\
\hline Aged over 50 years, $n(\%)$ & 1979 & 69 & 567 & 65 & 0.171 \\
\hline \multicolumn{6}{|l|}{ Ethnicity, n (\%) } \\
\hline Black & 1988 & 69 & 410 & 74 & $<0.001$ \\
\hline Coloured, mixed race & 465 & 16 & 96 & 17 & \\
\hline Indian & 306 & 11 & 41 & 7 & \\
\hline White & 128 & 4 & 11 & 2 & \\
\hline Rural, $n(\%)$ & 792 & 28 & 163 & 29 & 0.418 \\
\hline Education (years) & 10 & 7,13 & 9 & 6,12 & 0.028 \\
\hline Never been to school, $\mathrm{n}(\%)$ & 495 & 18 & 109 & 20 & 0.180 \\
\hline Never had paid employment, n (\%) & 1101 & 55 & 238 & 56 & 0.403 \\
\hline $\mathrm{BMI}\left(\mathrm{kg} / \mathrm{m}^{2}\right)$ & 28.8 & $23.9,33.7$ & 29.1 & $24.0,34.2$ & 0.540 \\
\hline Waist-to-height ratio & 0.59 & $0.52,0.67$ & 0.58 & $0.50,0.66$ & 0.070 \\
\hline Never used alcohol, n (\%) & 1576 & 80 & 353 & 83 & 0.052 \\
\hline Never used tobacco, n (\%) & 1635 & 83 & 367 & 86 & 0.023 \\
\hline Systolic BP (mm Hg) & 131 & 118,144 & 128 & 116,141 & 0.073 \\
\hline Diastolic BP (mm Hg) & 81 & 73,89 & 79 & 71,87 & 0.029 \\
\hline Hypertension, n (\%) & 1233 & 45 & 232 & 43 & 0.239 \\
\hline Diabetes, n (\%) & 248 & 13 & 46 & 11 & 0.355 \\
\hline
\end{tabular}

*Subsample: all respondents with spot UIC, valid 24-hour urine, sex and age recorded. Some variables may contain missing data as indicated by percentages. Data shown as median and IQR (25th, 75th percentiles) unless otherwise indicated. Hypertensive by measured BP $\geq 140$ and/ or $90 \mathrm{~mm} \mathrm{Hg}$ or previous diagnosis. Education, tobacco/alcohol use, ethnicity, employment and diabetes prevalence by self-report.

Continuous variables compared using independent samples Mann-Whitney U test, categorical variables compared using Pearson's $\chi^{2}$ test and Fisher's exact test.

BMI, body mass index; BP, blood pressure; SAGE, Study on global AGEing and adult health.

the total SAGE Wave 2 cohort $(\mathrm{n}=2887)$ in table 1 which included participants aged between 18 and 102 years with a body mass index (BMI) of 13.5-69.9. The subsample had a higher proportion of women and more black/ coloured respondents than the main cohort, which may explain differences in smoking, education and BP.

In the subsample that provided urine collections, median 24-hour urine volume was 1385 (IQR 900, 2278) $\mathrm{mL} /$ day, with a range from 500 to $4900 \mathrm{~mL} /$ day. Median urinary creatinine excretion was 1097 (IQR 790, 1682) $\mathrm{mg} / 24$ hours, with a range from 460 to $6441 \mathrm{mg} / 24$ hours. Median 24-hour Na excretion ( $\mathrm{n}=874$ ) was equivalent to a median salt intake of $6.3 \mathrm{~g}$ /day (range 1-43 g/day); $35 \%$ had values within the desirable range $(<5 \mathrm{~g}$ salt/day $)$, $37 \%$ had high values (5-9g salt/day) and $28 \%$ had very high values $(>9 \mathrm{~g}$ salt/day). We have previously reported that median salt intakes are higher in younger than older (50+ years) adults in this cohort $(8.6 \mathrm{~g} /$ day vs $6.1 \mathrm{~g} /$ day; $\mathrm{p}<0.001)$, and in urban compared with rural dwellers $(7.0 \mathrm{~g} / \text { day vs } 6.0 \mathrm{~g} / \text { day; } \mathrm{p}=0.033)^{38}$ but further analysis of $\mathrm{Na}$ versus iodine excretion, by demographic breakdown, is outside the scope of the current analysis. No significant difference in median UIE was found according to age category (18-49 years; $50+$ years) or sex; however, median UIE was significantly higher in urban compared with rural dwellers (128 (IQR 147) vs 115 (IQR 119); p=0.041). No demographic differences were found for MUIC. In the total sample, MUIC ( $\mathrm{n}=875$ ) was $130 \mu \mathrm{g} / \mathrm{L}(\mathrm{IQR}=58-202)$, indicating iodine sufficiency $(\geq 100 \mu \mathrm{g} / \mathrm{L})$, while median 24-hour UIE ( $\mathrm{n}=866$ ) was $117 \mu \mathrm{g} /$ day (IQR 138).

Both UIC and 24-hour iodine excretion differed across salt intake categories and were positively correlated with 24-hour salt intake, estimated from urinary $\mathrm{Na}$ excretion $(\mathrm{r}=0.166$ and 0.552 ; both $\mathrm{p}<0.001)$ (table 2$)$. In the lowest salt category of $<5 \mathrm{~g} /$ day, MUIC indicated borderline deficiency of $102 \mu \mathrm{g} / \mathrm{L}$ (table 3). According to median 24-hour UIE values, the group of participants with a salt intake of $<5 \mathrm{~g} /$ day is not meeting their dietary Estimated Average Requirement (EAR) of $95 \mu \mathrm{g} /$ day (Institute of Medicine 2003), ${ }^{39}$ with $58.4 \%$ having intakes below this value (table 3 ). Even in those with salt intakes in the moderately raised category of $5-9 \mathrm{~g} /$ day, a considerable proportion $(34.7 \%)$ had intakes below the EAR. Responses to questions on salt behaviours did not differ between participants across MUIC categories (data not shown), nor according to UIE (figure 1). 
Table 2 Spearman's rank-order and partial correlations between urinary iodine concentration, estimated salt intake and body size, SAGE South Africa Wave 2 (2015)

All $n=456$ Men $n=110$ Women $n=346$

\begin{tabular}{|c|c|c|c|c|}
\hline $\begin{array}{l}\text { Correlations with } \\
\text { spot UIC }(\mu \mathrm{g} / \mathrm{L})\end{array}$ & & & & \\
\hline \multirow[t]{2}{*}{$\begin{array}{l}\text { Salt intake (g/ } \\
\text { day) }\end{array}$} & $r$ & $0.166^{\star \star \star}$ & 0.164 & $0.153^{\star \star}$ \\
\hline & $p$ & 0.000 & 0.088 & 0.004 \\
\hline \multirow[t]{2}{*}{$\begin{array}{l}\text { 24-hour iodine } \\
\text { ( } \mu \mathrm{g} / \text { day) }\end{array}$} & $r$ & $0.423^{\star \star *}$ & $0.483^{* \star *}$ & $0.392^{\star \star \star}$ \\
\hline & $p$ & 0.000 & 0.000 & 0.000 \\
\hline \multirow[t]{2}{*}{ BMI $\left(\mathrm{kg} / \mathrm{m}^{2}\right)$} & $r$ & 0.036 & 0.001 & 0.096 \\
\hline & $p$ & 0.448 & 0.988 & 0.076 \\
\hline \multirow[t]{2}{*}{ Weight (kg) } & $r$ & 0.043 & 0.035 & 0.056 \\
\hline & $p$ & 0.365 & 0.716 & 0.299 \\
\hline \multirow[t]{2}{*}{$\begin{array}{l}\text { Waist } \\
\text { circumference } \\
\text { (cm) }\end{array}$} & $r$ & 0.001 & 0.027 & 0.008 \\
\hline & $p$ & 0.991 & 0.784 & 0.878 \\
\hline \multirow[t]{2}{*}{$\begin{array}{l}\text { Hip } \\
\text { circumference } \\
\text { (cm) }\end{array}$} & $r$ & 0.040 & $0.213^{*}$ & 0.008 \\
\hline & $p$ & 0.389 & 0.026 & 0.883 \\
\hline
\end{tabular}

Correlations with

24-hour UIE ( $\mu \mathrm{g}$ /

day)

\begin{tabular}{|c|c|c|c|c|}
\hline $\begin{array}{l}\text { Salt intake (g/ } \\
\text { day) }\end{array}$ & r & $0.552^{\star \star \star}$ & $0.504^{\star \star *}$ & $0.561^{\star * *}$ \\
\hline & $p$ & 0.000 & 0.000 & 0.000 \\
\hline \multirow[t]{2}{*}{ BMI $\left(\mathrm{kg} / \mathrm{m}^{2}\right)$} & $r$ & 0.092 & 0.030 & $0.168^{\star *}$ \\
\hline & $p$ & 0.051 & 0.758 & 0.002 \\
\hline \multirow[t]{2}{*}{ Weight (kg) } & r & $0.130^{\star *}$ & -0.023 & $0.193^{\star \star *}$ \\
\hline & $p$ & 0.005 & 0.814 & 0.000 \\
\hline \multirow[t]{2}{*}{$\begin{array}{l}\text { Waist } \\
\text { circumference } \\
\text { (cm) }\end{array}$} & r & 0.032 & -0.011 & 0.069 \\
\hline & $p$ & 0.491 & 0.911 & 0.200 \\
\hline \multirow[t]{2}{*}{$\begin{array}{l}\text { Hip } \\
\text { circumference } \\
\text { (cm) }\end{array}$} & r & 0.052 & 0.056 & 0.094 \\
\hline & $p$ & 0.269 & 0.563 & 0.080 \\
\hline
\end{tabular}

Correlations between iodine and body size controlled for salt intake.

Correlation is significant at the ${ }^{*} \mathrm{p}<0.05$ level; ${ }^{* *} \mathrm{p}<0.01$ level; or ${ }^{* * *} \mathrm{p}<0.001$ level.

BMI, body mass index; SAGE, Study on global AGEing and adult health; UIC, spot urinary iodine concentration; UIE, 24hour urinary iodine excretion.

\section{DISCUSSION}

Our study found that in a sample of South African adults, those with a salt intake within the WHO recommended range of less than $5 \mathrm{~g} /$ day had suboptimal iodine intakes, whereas those with higher salt intakes were shown to have adequate intakes, using 24-hour UIE as a biomarker of intake. Thus, there is a risk that sodium reduction strategies may impact adversely on iodine intakes and result in populations being at risk of inadequate iodine intakes unless fortificant levels of iodine in salt are revised accordingly.

These data were collected immediately prior to introduction of South Africa's mandatory salt reduction legislation, which requires food manufacturers to comply with maximum salt targets across a wide range of processed foods. The impact of the salt reduction policy on iodised salt intake is unknown. South Africa has had a well-functioning table salt iodisation programme since 2005, but salt used in food processing is exempt from mandatory iodisation. Despite iodised salt not being required by law to be used as an ingredient in the manufacturing of processed foods, a study ${ }^{40}$ that investigated the iodine content of salt used in bread, margarine and salty snack flavourings in 2002 provided surprising results. Even though 11 of the 12 manufacturers surveyed at that time reported that they used non-iodised salt in their processed foods, substantial amounts of iodine were found in the salt used by a third of these manufacturers' products, with a mean content of 39-69 ppm, and these were the items that were mostly distributed countrywide. An appreciable percentage of the food companies used iodised salt unknowingly in the manufacturing of frequently consumed processed foods, and this may have had a considerable impact on the daily iodine intake of consumers. To our knowledge, there is no updated information on the use of iodised salt in food processing by food manufacturers. Thus, it is feasible that the salt reduction legislation that targets salt reduction in processed foods may also impact on contribution of total dietary iodine intake.

As well as changes to the food supply, nutrition education activities undertaken by the Department of Health and non-governmental organisations in South Africa aim to change consumer behaviour related to table salt use. $^{4142}$ The timing of the WHO-SAGE Salt \& Tobacco substudy in South Africa was planned to provide a baseline population salt intake ${ }^{38} 1$ year before mandatory salt legislation, in order for comparison in the same cohort 1 year after introduction of the legislation ${ }^{29}$ in SAGE Wave 3 . The data reported in this paper relate to the presalt reduction legislation baseline timepoint. Inclusion of iodine analyses in Wave 3 in 2018 will further allow evaluation of the compatibility of iodine fortification and salt reduction policies.

Concerted efforts are being made in many countries to lower salt consumption. ${ }^{18}$ Because the primary food vehicle for iodine fortification is salt, there is concern that decreasing salt consumption will increase the risk of iodine deficiency. Our study findings indicate that this is a potential public health problem. Our findings are in contrast to those reported from a sample of adult men and women surveyed in Cape Town in 2004, when UIC did not differ across categories of salt intake. ${ }^{21}$ Reasons for this are unclear but may reflect a simultaneous increased consumption of salt provided from non-iodised 
Table 3 Urinary iodine, estimated iodine intake and sodium excretion values by salt intake equivalent categories

\begin{tabular}{|c|c|c|c|c|c|c|c|c|c|}
\hline & \multicolumn{9}{|c|}{ 24-hour urinary sodium excretion } \\
\hline & \multicolumn{2}{|c|}{ All $n=874^{*}$} & \multicolumn{2}{|c|}{ Salt $<5 \mathrm{~g} /$ day $n=307$} & \multicolumn{2}{|c|}{ Salt $5-9 \mathrm{~g} /$ day $n=322$} & \multicolumn{2}{|c|}{ Salt $>9 \mathrm{~g} /$ day $n=245$} & \multirow[b]{2}{*}{$P$ value } \\
\hline & Median & IQR & Median & IQR & Median & IQR & Median & IQR & \\
\hline Salt (g/day) & 6.3 & $3.7,9.0$ & 3.6 & $2.8,4.5$ & 6.8 & $5.7,7.9$ & 12.3 & $9.3,15.4$ & $<0.001$ \\
\hline UIC ( $\mu \mathrm{g} / \mathrm{L})$ & 130 & 58,202 & 102 & 32,172 & 131 & 56,206 & 149 & 78,220 & $<0.001$ \\
\hline $\begin{array}{l}\text { Estimated iodine } \\
\text { intake }(\mu \mathrm{g} / \text { day }) \dagger\end{array}$ & 127 & 52,202 & 80 & 40,120 & 130 & 63,197 & 212 & 127,297 & $<0.001$ \\
\hline $\begin{array}{l}\% \text { with daily iodine } \\
\text { intake below EAR } \\
\text { for iodine }(95 \mu \mathrm{g} / \\
\text { day) }\end{array}$ & 37.1 & & 58.4 & & 34.7 & & 13.5 & & \\
\hline
\end{tabular}

${ }^{*}$ One individual in subsample with missing 24-hour sodium analysis. Data shown as median and IQR (25th, 75th percentiles). Continuous variables compared using independent samples Kruskal-Wallis test.

†Daily iodine intake assumed as $24-$ hour UIE $(\mu \mathrm{g} /$ day $) / 0.92$ to account for bioavailability.

EAR, Estimated Average Requirement; UIC, spot urinary iodine concentration; UIE, 24-hour urinary iodine excretion.

sources in processed foods, accompanied by a reduction in discretionary iodised salt intake over the past decade. However, data are not available to further postulate in this regard.

The South African strategic plan to reduce cardiovascular disease includes the target to reduce the population intake of salt to less than $5 \mathrm{~g}$ /day. At present, the salt intake is higher than this level, with older reports from the early 2000 s estimating that $40 \%$ salt was provided from discretionary salt intake. ${ }^{22}$ The salt intake estimations in the current study include both added (discretionary) and non-discretionary salt intakes but the lack of data on dietary intakes of the participants prevents further investigation of the source of the salt.

We hypothesise that food manufacturers may have already reduced salt content in processed foods at the time of the study (2015), and that some of these products may have been produced with iodised salt. If this is the case, this would result in lowered iodine intake at the same time as lowered salt intake, as would any reduction in discretionary salt use. Considering the latter, there have been many accompanying health education strategies that target salt reduction behaviours, alongside the salt legislation in processed

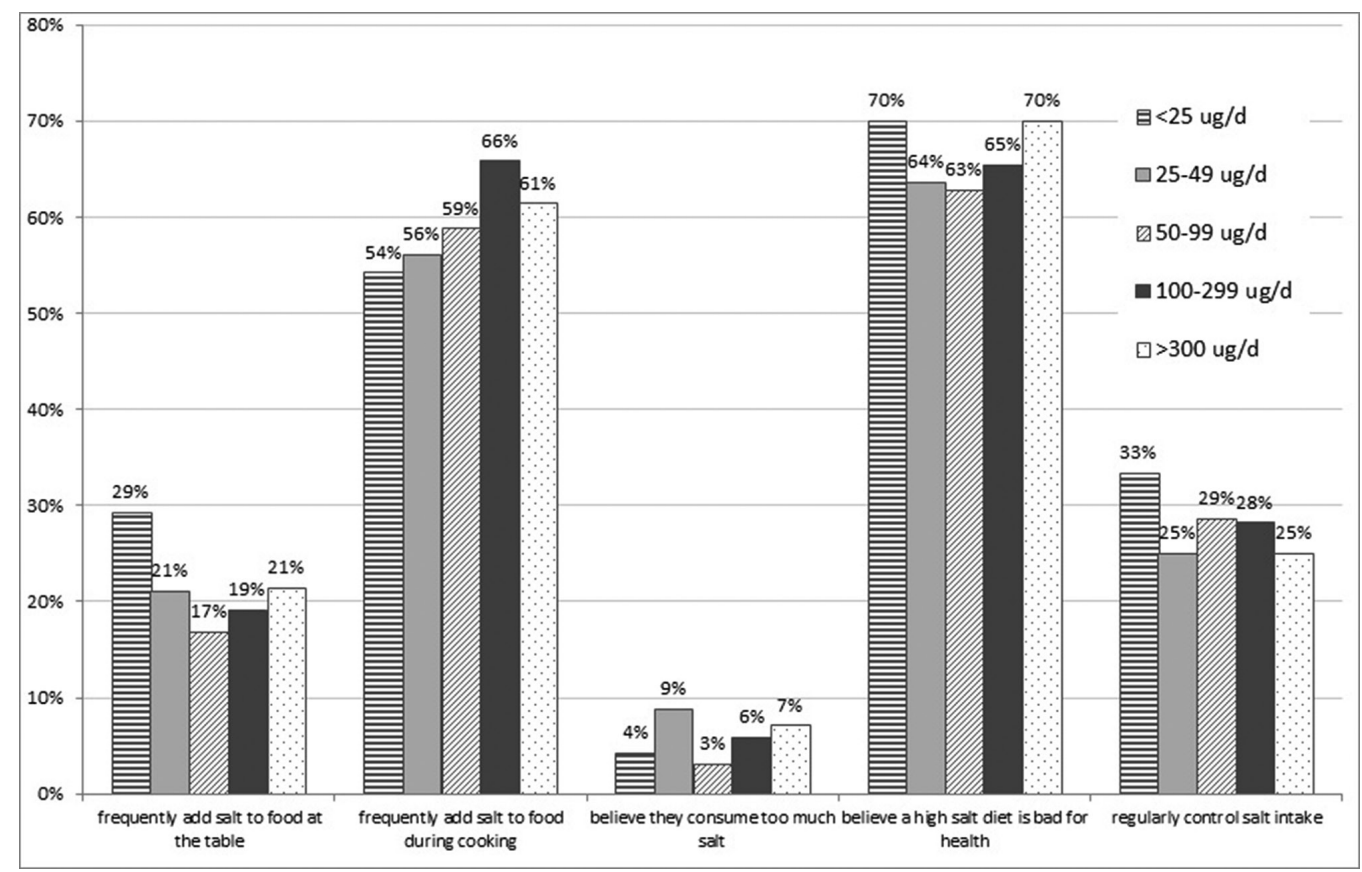

Figure 1 Self-reported salt knowledge, attitudes and behaviour by 24-hour urinary iodine excretion (UIE; n=539). 
foods. ${ }^{42}$ In 2015, a mass media campaign (Saltwatch) using television, radio advertisement and other platforms for information dissemination was undertaken to increase public awareness related to the association between a high salt intake, BP and cardiovascular disease in South Africa. The campaign, conducted by the Heart and Stroke Foundation of South Africa with funding from the Department of Health, focused on the need to reduce discretionary salt intake. Evaluation of the programme undertaken in 550 black women, aged 18-55 years in three provinces, identified that there was an increase in most of the indicators of knowledge, attitudes and behaviour change towards considering and initiating reduced salt consumption following the campaign. ${ }^{41}$ Significant increases were found for knowledge items related to high salt intake and its health outcomes. Participants also reported that they added less salt while cooking and at the table. In the current study, responses to questions on salt behaviours did not differ between participants across MUIC categories, nor according to 24-hour UIE. This could mean that the questions are not sufficiently sensitive to discern between salt intake behaviours, or that the contribution of discretionary salt to total iodine intake is influenced by other food sources of iodised salt.

A strength of the current study was use of the gold standard method for assessment of salt intake, namely 24-hour urinary collections. Limitations relate to the high number of respondents with missing or incomplete urine samples. The difficulty in obtaining complete 24-hour urine samples is well known, and the comparison between the main study cohort and those providing complete samples shows that men, and those with higher education less frequently provided complete 24-hour urine. This may also reflect the nature of the survey as fieldworkers visited the respondent's homes and those who were away with work were less likely to have taken part or would have potentially had more difficulty with the urine collection, creating a selection bias in the data towards the population with lower employment levels. Future research may consider workplace-based data collection. An assumption was made regarding cut-off values for completeness of 24-hour urine collection where urinary volume $<300 \mathrm{~mL} /$ day or creatinine excretion $\leq 4 \mathrm{mmol} /$ day $\left(\right.$ women) or $\leq 6 \mathrm{mmol} /$ day $(\mathrm{men})^{33}$ were the criteria used for exclusion purposes. In populations with low protein intakes, daily creatinine excretion is more variable than in well-nourished populations, and often lower than $1 \mathrm{~g}(8.84 \mathrm{mmol}) /$ day. ${ }^{43} \mathrm{~A}$ limitation of the study is that neither dietary protein intake nor lean body mass was assessed which makes it difficult to account for these two confounding variables when deciding on how to interpret low urinary creatinine concentrations. It is possible that the use of higher creatinine excretion cut-off reference values as a measure of completeness of urine collection may have resulted in a somewhat lower number of subjects considered to be at risk of inadequate iodine nutrition, as well as a higher estimated salt intake.

A further limitation is the lack of dietary data on sources of iodine provided by foods other than iodised salt. Iodine-rich dietary sources include fish and seafood, and dairy products, and it is possible that some of these foods may also be high in salt, as in the case of salted dried fish commonly consumed by the coloured population (known as 'bokkems'). However, generally these foods are not major contributors to sodium in the South African diet. ${ }^{22}$ Interestingly, in women, both UIC and UIE correlated positively with BMI, independently of salt intake. Looking at changes in food consumption patterns in South Africa over time, it seems that there is an increase in processed foods and in other foods that may contribute to iodine intake independently of iodised salt such as fish, eggs, seafood and dairy foods. ${ }^{44}$ The contribution of food sources, other than iodised salt, to total iodine intake warrants further investigation in the context of evaluating the mandatory salt iodisation programme in South Africa. Furthermore, this study presents limited data for women of childbearing age and no data for children. Further work is needed to determine if there is an impact of the sodium reduction legislation in these particularly iodine-sensitive groups.

\section{CONCLUSION}

This study highlights the need to closely monitor the iodine status of populations as they undergo population-level reductions in salt intake, in countries where mandatory salt iodisation is implemented. Even at salt intake levels currently above the WHO target of $5 \mathrm{~g} /$ day, there was a considerable proportion with iodine intakes below the EAR. This indicates there may be a need to increase the level of iodine in fortified table salt. Alternatively, compulsory iodisation of salt used in the production of some staple foods such as bread may be considered. In a country where some sectors of the population may be exposed to excessive iodine intakes, this strategy would require careful dietary modelling before being pursued. It is recommended that surveys that measure urinary $\mathrm{Na}$ excretion also simultaneously measure UIC and determine the iodine content in table salt collected from households.

\section{Author affiliations}

${ }^{1}$ School of Medicine, University of Wollongong, Wollongong, New South Wales, Australia

${ }^{2}$ Research Fellow, Illawarra Health and Medical Institute, Wollongong, New South Wales, Australia

${ }^{3}$ Hypertension in Africa Research Team (HART), North-West University, Potchefstroom, South Africa

${ }^{4}$ Developmental Pathways for Health Research Unit, University of the Witwatersrand, Johannesburg, South Africa

${ }^{5}$ Centre of Excellence in Nutrition, North-West University, Potchefstroom, South Africa 
${ }^{6}$ Statistical Consultation Services, North-West University, Potchefstroom, South Africa

${ }^{7}$ MRC Unit for Hypertension and Cardiovascular Disease, North-West University, Potchefstroom, South Africa

${ }^{8}$ WHO Multi-Country Studies Unit, World Health Organization (WHO), Geneva, Switzerland

${ }^{9}$ Research Centre for Generational Health and Ageing, University of Newcastle, Newcastle, New South Wales, Australia

Acknowledgements The authors thank all the respondents for contributions and also Dr Stephen Rule, Dr Robin Richards and Mr Godfrey Dlulane of Outsourced Insight who were subcontracted to conduct the surveys and coordinate data collection within South Africa.

Contributors KC, PK and NN designed the research. LJW implemented the research. JB analysed the iodine samples. MC, LJW and KC analysed the data. KC, LJW, JB, AES, MC and PK wrote the paper. KC takes responsibility for the contents of this article. All authors read and approved the final manuscript.

Funding This work is supported by an agreement with the CDC Foundation with financial support provided by Bloomberg Philanthropies and a Partnerships \& Research Development Fund (PRDF) grant from the Australia Africa Universities Network. SAGE is supported by WHO and the Division of Behavioral and Social Research (BSR) at the National Institute on Aging (NIA), US National Institutes of Health, through interagency agreements with WHO (OGHA 04034785; YA13239089CN90020; Y19AG91005901) and a research project grant (R01AG034479).

Disclaimer The content of this manuscript is solely the responsibility of the authors and does not necessarily represent the official views of the WHO or the funding bodies.

Competing interests None declared.

Patient consent Obtained.

Ethics approval WHO Ethics Review Committee (RPC149), and North-West University and University of Witwatersrand Research Ethics Committees in South Africa .

Provenance and peer review Not commissioned; externally peer reviewed.

Data sharing statement The data set is available on request and will form part of the data catalogue of the WHO Study on global AGEing and adult health (SAGE) (http://apps.who.int/healthinfo/systems/surveydata/index.php/catalog/sage/about).

Open Access This is an Open Access article distributed in accordance with the Creative Commons Attribution Non Commercial (CC BY-NC 4.0) license, which permits others to distribute, remix, adapt, build upon this work non-commercially, and license their derivative works on different terms, provided the original work is properly cited and the use is non-commercial. See: http://creativecommons.org/ licenses/by-nc/4.0/

(c) Article author(s) (or their employer(s) unless otherwise stated in the text of the article) 2018. All rights reserved. No commercial use is permitted unless otherwise expressly granted.

\section{REFERENCES}

1. Andersson M, de Benoist $B$, Delange $F$, et al. Prevention and control of iodine deficiency in pregnant and lactating women and in children less than 2-years-old: conclusions and recommendations of the Technical Consultation. Public Health Nutr 2007:10:1606-11.

2. World Health Organization. United Nations Children's Fund; International Council for the Control of lodine Deficiency Disorders. Assessment of iodine deficiency disorders and monitoring their elimination: a guide for programme managers. 3rd ed. Geneva: World Health Organization, 2007.

3. WHO Guideline on Fortification of food-grade salt. WHO: Geneva, 2014. http://www.who.int/nutrition/publications/guidelines/ fortification foodgrade saltwithiodine/en/.

4. United Nations System. Standing Committee on Nutrition (SCN) News. Universal Salt lodisation. 35, 2007. ISSN 1564-3743. (accessed $17 \mathrm{Jul}$ 2017)

5. United Nations Children's Fund (UNICEF). The State of the World's Children. New York: UNICEF, 2016. https://www.unicef.org/ sowc2016/. (cited 12 Jan 2018).

6. The lodine Global Network. Global lodine Nutrition Scorecard. Zurich, 2016. http://www.ign.org/cmdata/Scorecard_2016_SAC PW. pdf. (accessed 12 Jan 2018).
7. Gizak M, Gorstein J, Andersson M. Epidemiology of lodine Deficiency. Pearce E, ed. lodine Deficiency Disorders and Their Elimination. Ebook. 35: Springer, 2017. https://link.springer.com/ book/10.1007/978-3-319-49505-7.

8. Andersson M, Karumbunathan V, Zimmermann MB. Global iodine status in 2011 and trends over the past decade. J Nutr 2012:142:744-50.

9. The lodine Global Network. Global iodine nutrition scorecard 2015. Zurich: The lodine Global Network, 2015. http://www.ign.org/cmdata/ Scorecard 2015 August 26 new.pdf. (cited 1 Jan 2018).

10. Zimmermann MB, Jooste PL, Pandav CS, et al. lodine-deficiency disorders. The Lancet 2008:372:1251-62.

11. Effects of mandatory iodization on the iodine content of retailers and household salt in South Africa. 8th World Salt Symposium, 2000.

12. Joint FAO/WHO Expert Committee on Food Additives. WHO Technical Report Series, No. 806, Annex 5. Geneva: World Health Organization, 1991.

13. Jooste P, Zimmermann M. Progress towards eliminating iodine deficiency in South Africa. South African Journal of Clinical Nutrition 2008;21:8-14.

14. Jooste PL, Labadarios $\mathrm{D}, \mathrm{Nel} \mathrm{H}$, et al. lodine content of household salt, drinking water and iodine status of women and children. National Food Consumption Survey-Fortification baseline (NFCS-FB): South Africa 2005. Stellenbosch, South Africa, 2007:387-407.

15. Labadarios D, Swart R, Maunder E, et al. The National Food Consumption Survey-Fortification Baseline (NFCS-FB): South Africa, 2005. Pretoria: Directorate: Nutrition, Department of Health, 2007.

16. Jooste PL, Weight MJ, Lombard CJ. lodine concentration in household salt in South Africa. Bull World Health Organ 2001;79:534-40.

17. Webster JL, Dunford EK, Hawkes C, et al. Salt reduction initiatives around the world. $J$ Hypertens 2011;29:1043-50.

18. Trieu K, Neal B, Hawkes $C$, et al. Salt Reduction Initiatives around the World - A Systematic Review of Progress towards the Global Target. PLoS One 2015;10:e0130247.

19. Charlton K, Webster J, Kowal P. To legislate or not to legislate? A comparison of the UK and South African approaches to the development and implementation of salt reduction programs. Nutrients 2014;6:3672-95.

20. Charlton KE, Steyn K, Levitt NS, et al. Ethnic differences in intake and excretion of sodium, potassium, calcium and magnesium in South Africans. Eur J Cardiovasc Prev Rehabil 2005;12:355-62.

21. Charlton KE, Steyn K, Levitt NS, et al. A food-based dietary strategy lowers blood pressure in a low socio-economic setting: a randomised study in South Africa. Public Health Nutr 2008;11:1397-406.

22. Charlton KE, Steyn K, Levitt NS, et al. Diet and blood pressure in South Africa: Intake of foods containing sodium, potassium, calcium, and magnesium in three ethnic groups. Nutrition 2005;21:39-50.

23. Report number R214: Foodstuffs, cosmetics and disinfectants Act, 1972 (Act 54 of 1972). Regulations relating to the reduction of sodium in certain foodstuffs and related matters: South African Department of Health, 2013.

24. Bertram MY, Steyn K, Wentzel-Viljoen E, et al. Reducing the sodium content of high-salt foods: effect on cardiovascular disease in South Africa. S Afr Med J 2012;102:743-5.

25. Watkins DA, Olson ZD, Verguet S, et al. Cardiovascular disease and impoverishment averted due to a salt reduction policy in South Africa: an extended cost-effectiveness analysis. Health Policy Plan 2016;31:75-82.

26. Verkaik-Kloosterman J, van 't Veer P, Ocké MC. Reduction of salt: will iodine intake remain adequate in The Netherlands? Br J Nutr 2010;104:1712-8.

27. Charlton KE, Jooste PL, Steyn K, et al. A lowered salt intake does not compromise iodine status in Cape Town, South Africa, where salt iodization is mandatory. Nutrition 2013;29:630-4.

28. Kowal P, Chatterii S, Naidoo N, et al. Data resource profile: the World Health Organization Study on global AGEing and adult health (SAGE) Int J Epidemiol 2012;41:1639-49.

29. Charlton $\mathrm{K}$, Ware LJ, Menyanu $\mathrm{E}$, et al. Leveraging ongoing research to evaluate the health impacts of South Africa's salt reduction strategy: a prospective nested cohort within the WHO-SAGE multicountry, longitudinal study. BMJ Open 2016;6:e013316.

30. World Medical Association. Declaration of Helsinki - Ethical principles for medical research involving human subjects (as amended by the 64th WMA General Assembly, Fortaleza, Brazil, October 2013, 2013. https://www.wma.net/policies-post/wmadeclaration-of-helsinki-ethical-principles-for-medical-researchinvolving-human-subjects/).

31. WHO/PAHO Regional Expert Group for Cardiovascular Disease Prevention through Population-wide Dietary Salt Reduction. Protocol 
for population level sodium determination in 24-hour urine samples. Geneva: World Health Organization, 2010.

32. Nicar MJ, Hsu MC, Johnson T, et al. The preservation of urine samples for determination of renal stone risk factors. Lab Med 1987:18:382-4.

33. Stolarz-Skrzypek K, Kuznetsova T, Thijs L, et al. Fatal and nonfatal outcomes, incidence of hypertension, and blood pressure changes in relation to urinary sodium excretion. JAMA 2011;305:1777-85.

34. Ohashi T, Yamaki M, Pandav CS, et al. Simple microplate method for determination of urinary iodine. Clin Chem 2000;46:529-36.

35. Caldwell KL, Makhmudov A, Jones RL, et al. EQUIP: a worldwide program to ensure the quality of urinary iodine procedures. Accreditation and Quality Assurance 2005;10:356-61.

36. Delange F, de Benoist B, Burgi H. ICCIDD Working Group. International Council for Control of lodine Deficiency Disorders. Determining median urinary iodine concentration that indicates adequate iodine intake at population level. Bull World Health Organ 2002;80:633-6.

37. Karmisholt J, Laurberg P, Andersen S. Recommended number of participants in iodine nutrition studies is similar before and after an iodine fortification programme. Eur J Nutr 2014;53:487-92.

38. Ware LJ, Charlton K, Schutte AE, et al. Associations between dietary salt, potassium and blood pressure in South African adults: WHO SAGE Wave 2 Salt \& Tobacco. Nutr Metab Cardiovasc Dis 2017;27:784-91.
39. Institute of Medicine Academy of Sciences, USA. Dietary Reference Intakes for Vitamin A, Vitamin K, Arsenic, Boron, Chromium, Copper, lodine, Iron, Manganese,Molybdenum, Nickel, Silicon, Vanadium and Zinc. Washington, DC: The National Academies Press, 2001. https:// www.ncbi.nlm.nih.gov/pubmed/25057538.

40. Harris MJ, Jooste PL, Charlton KE. The use of iodised salt in the manufacturing of processed foods in South Africa: bread and bread premixes, margarine, and flavourants of salty snacks. Int J Food Sci Nutr 2003;54:13-19.

41. Wentzel-Viljoen E, Steyn K, Lombard C, et al. Evaluation of a MassMedia Campaign to Increase the Awareness of the Need to Reduce Discretionary Salt Use in the South African Population. Nutrients 2017:9:1238.

42. Webster J, Crickmore C, Charlton K, et al. South Africa's salt reduction strategy: Are we on track. and what lies ahead? SAMJ: South African Medical Journal 2017;107:20-1.

43. Bourdoux P. Evaluation of the iodine intake: problems of the iodine/creatinine ratio--comparison with iodine excretion and daily fluctuations of iodine concentration. Exp Clin Endocrinol Diabetes 1998;106:S17-S20.

44. Ronquest-Ross L-C, Vink N, Sigge G. Department of Food Science, Stellenbosch University, Stellenbosch, South Africa. Food consumption changes in South Africa since 1994. S Afr J Sci 2015;111:1-12. 